\title{
The Conflicting Case of Lev Davidovich Landau's Cerebral Death
}

\author{
Celso Luis Levada ${ }^{1}$, Huemerson Maceti ${ }^{2}$, Ivan José Lautenschleguer ${ }^{3}$, Miriam de Magalhães \\ Oliveira Levada ${ }^{4}$ \\ 1, 2, 3,4 Teaching Group of Sciences of Herminio Ometto Foundation - Uniararas /Brazil
}

*Corresponding Author: Celso Luis Levada, Teaching Group of Sciences of Herminio Ometto

Foundation - Uniararas /Brazil

\begin{abstract}
On April 1, 2018, it will complete fifty years of the death of one of the scientists who contributed most to the development of physics in the 20th century, the Russian Lev Davidovich Landau. He was born on January 22, 1908 in Baku, Azerbaijan, in what was then the Russian Empire. He was a prominent soviet physicist who made fundamental contributions to many areas of theoretical physics. He received the 1962 Nobel Prize in Physics for his theory of super fluidity that accounts for the properties of liquid helium. On January, 1962, Landau was seriously injured in an automobile accident and remained three months in a coma, being declared clinically dead four times. Recovered, he lived another six years. Landau died on April, 1968, aged 60, from complications from the accident. The case involving Landau introduces a conflict related to the removal of organs from people believed to be brain dead.
\end{abstract}

Keywords: Landau, Nobel Prize Physics, Brain Death.

\section{INTRODUCTION}

Landau was born in Baku, Azerbaijan, on January 22, 1908, the son of an oil engineer and a doctor. At the age of thirteen Landau was recognized as a prodigious boy in physical sciences and mathematics. In 1922, at the age of 14, he entered Baku University, where he studied Physics, Mathematics and Chemistry at the same time, graduating at the Technical Institute of Physics in Leningrad at the age of 19 .

At the age of 21, at the University of Leningrad, he received his PhD in Sciences and was sent to Copenhagen to work at the Institute of Theoretical Physics with Niels Bohr. Landau was the most brilliant scientist in the Soviet Union and one of the most prominent worldwide, having received the Nobel Prize for Physics in 1962. The minor planet Landau 2142 discovered in 1972 and the lunar crater Landau are named in his honor.

An automobile accident took him to the hospital and, after being declared clinically dead four times, lived another six years. The Landau case introduces some conflict related to a very common medical problem, the withdrawal of organs from people regarded as brain dead. In medicine there are countless records of patients who have recovered, so proposals on euthanasia should be viewed with great caution. Some doctors talk about limiting treatment, which means recognizing they may even go to save someone. But how to know the limit?

According to DINI ${ }^{(5)}$, of all the themes of bioethics, the situations related to the end of life represent the most controversial situations. Although death is intrinsic to the human condition, its enunciation and moral negotiation presuppose a redefinition of moral values rooted in the socialization of health professionals.

As historian DOROZYNSKI ${ }^{(7)}$ mentions, Landau arrived at the Moscow hospital in January 1962, a victim of an automobile disaster and, in addition to having lost much blood, suffered many fractures and serious injuries to the heart, lungs, brain, kidneys and central nervous system.

He remained in a coma for more than three months. Besides the general condition being very bad, his body did not respond to the treatment of the medicines applied. The Russian government summoned neurologists from the main countries of the world and all gave it for dead, that is, they verified the brain death. Landau's wife demonstrated a great ability to influence the Russian authorities in order to 
ensure that doctors would not turn off the devices that kept him alive. At the insistence of the family and, because he represented one of the greatest scientists of all time from Russia, the request was granted.

The leading neurologists in the world were mistaken for the prognosis and if they had disconnected the respirator Landau would have died by a hasty assessment. At the end of 1963 he was discharged from the hospital and was able, although with limitations, to return some activities, including traveling to Stockholm to receive the Nobel Prize in Physics. Between 1962 and 1963 his heart stopped four times, and he had been artificially revived, which prompted one historian to write the book "Landau, the wise man who died four times". But in April 1968, his heart stopped for the fifth and last time.

\section{EUTHANASIA}

In the area of human health, many benefits have been obtained with the technological advance, for example, the reversibility in the evolution of a great number of diseases and the increase in the life expectancy of the population. However, in the case of certain diseases, at a given moment, even if all resources are available, the patient's situation is headed for the inevitable death process. In some cases, death is slow and painful, as is the situation of terminally ill patients who undergo prolonged treatments without results.

Euthanasia, the possibility of discontinuation of treatment that is prolonging the suffering of the patient, can be seen as a solution. However, there is a dilemma, for what is a solution for some is a problem for others, since there are ethical, religious, moral and legal implications (BATISTA and SCHARAMM (2)).

Thus, many scholars believe that when therapeutic measures do not increase survival, it is necessary to make decisions to continue or discontinue treatment. In general, decisions of this nature should be made by the family, the medical staff, and the patient when possible. Therefore, it is important to make an accurate diagnosis of the death of an individual. Perhaps thousands of patients are delivered to suffering without a prospect of recovery in hospitals, but euthanasia is considered by many to be a violation of God's law, an offense against human dignity and a crime against life (ARAÚJO and VIEIRA (1)).

\section{THE LEGISLATION}

It is the brain-dead patient who provides viable organs for transplantation. If a family member knows that the patient wishes to be an organ donor, the best way to ensure that the patient's wishes are honored is to inform the medical staff. The legislation in Brazil directs the prospective donor to sign a card in his / her lifetime that informs his / her wish to donate the organs that can be included in the documents.

As it is deduced from the article by MARQUES SOUZA ${ }^{(11)}$, currently the concept of death corresponds to encephalic death, which is the total and definitive abolition of the activities of the encephalon, where the commands of life are interrupted, not emanating impulse from any nerve center. According to FREIRE DE SÁ ${ }^{(10)}$, the criterion for the diagnosis of brain death is the irreversible cessation of all functions of the brain, including the brainstem, responsible for the maintenance of autonomic vital processes, such as blood pressure and respiratory function. On the other hand, DUARTE ${ }^{(8)}$ says that, in declaring the death of a person, the physician will be, through this practice, also declaring that the personality of that individual has extinguished, since such extinction is due to the death event. In addition to the ordinary verification, which is based on clinical examination, other criteria should be used to verify the person's death, namely, that there is no brain activity, as well as, that there is no blood circulation. Thus, the physician is responsible for attesting to the occurrence of "causa mortis" certificate, whose main purpose is to confirm the occurrence of the event and the definition of the death cause.

Death is decreed, according to medicine, and under the terms of Law number 9.434/1973, if it is confirmed and registered by two physicians, one of them specialist in Neurology. In the LANDAU case, the Russian government has summoned neurologists from the main countries of the world, and everyone has considered him dead. 


\section{LANDAU'S BIOGRAPHICAL DATA AND SOME FACTS ABOUT HIS LIFE}

According to CARUSO and BASSALO ${ }^{(13)}$, between 1929 and 1931, Landau traveled abroad with a scholarship from the Soviet government, and from the Rockefeller Foundation, the US government. In this way, he studied with the greatest physicists of the time. In Germany, for example, he worked with Nobel Prize-winning physicists such as Max Born and Werner Karl Heisenberg in Switzerland and with the Austro-Swiss physicist Wolfgang Pauli, winner of the Nobel Prize in Physics in 1945. In England, Landau worked with physicist and chemist Sir Ernest Rutherford (Nobel Prize for Chemistry in 1908) and in Copenhagen, he worked with the Danish physicist and Nobel Prize in Physics in 1922, Niels Bohr.

From 1932 to 1937, Landau headed the Department of Theoretical Physics of the Ukrainian Physical and Technological Institute (UIFT) in Kharkov in Ukraine.

In this Department, the issues Landau was studying were often very complex; to solve them, he employed his great mathematical ability and his physical intuition, which allowed him to formulate new concepts and even make accurate predictions.

Owing the unmistakable brand of genius, his theory of quantum liquids even today, after more than fifty years, is much revered. With numerous contributions in all branches of physics, he represents to be one of the great responsible for the theoretical advances of Science in the twentieth century.

He was awarded the Nobel Prize in 1962 for his pioneering theories of modern physics, especially helium in liquid form at minus 270 degrees Celsius. In addition, he wrote a collection of theoretical physics books that is still a reference in our day.

Landau's work is peculiar and complete, quite distinct from other theoretical physicists. Today, after more than a hundred years, Landau is a legend. He was the great inspirer and promoter of the famous school of Soviet theoretical physics, of which Abrikosov, one of his disciples, was awarded the Nobel Prize in Physics.

In addition to his findings in theoretical physics, Landau was the main founder of the great tradition of theoretical physics in the Soviet Union, centered in Kharkiv, Ukraine, now, which is often referred to as the Landau School. Its demand was enormous, having established the so-called "Landau minima", a very rigorous test for young physicists. He wrote with Lifschitz the Theoretical Physics Course, in ten volumes which is still a fundamental reference in any bibliography of physics.

According to CARUSO and BASSALO ${ }^{(13)}$, Landau had a special way of doing and studying physics, because he rarely read a theoretical article until the end, just looked around to see the path followed by the author. Then he would make his own calculations and, if they agreed with the author's calculations, he would approve the work in question. At Landau's school, students were also advised to think less about fundamentals and solve difficult problems, calculating non-trivial effects in surveys, with Landau being the final arbiter. The members of the Landau's school valued very precise and concrete results and were proud of the wide range of effects explained and predicted.

\section{LANDAU'S SOME WORKS}

According to LIVANOVA ${ }^{(6)}$, Landau's work covers a very wide range of topics and has had a considerable impact on all areas of physics, including condensed matter physics, plasma, high energy and particle physics, fluid dynamics, astrophysics, gravitation, elasticity, etc. Together with the Russian physicist Evgeny Mikhaillovich Lifshitz, he wrote the ten-volume collection of the magnificent world-renowned Theoretical Physics Course which covered topics ranging from mechanics, classical field theory, quantum mechanics, continuous media electrodynamics, fluid dynamics, kinetic theory, elasticity theory, statistical physics, and more. This collection is used to this day.

In his Nobel-winning work, Landau thought of superfluid Helium as a quantum fluid so that its atoms behave as if they were in the same quantum state. Their movements are highly correlated, improving the physical properties of the super fluidity state and he also introduced the notion of quasiparticles, which act as carriers of motion in the liquid.

This is an important concept applied in many other phenomena in condensed matter physics. Another famous contribution of condensed matter physics is the Ginzburg-Landau theory of superconductivity, 
which is a mathematical way of describing the properties of superconductors with the aid of general thermodynamic arguments. The Ginzburg-Landau theory lends itself to very interesting studies such as the problem of thermodynamic fluctuations near phase transitions to the superconducting state. This problem has a very strong dependence on the dimensionality of the studied system, being especially useful for the understanding of superconductors that can be understood as a second transition from the normal order to the superconducting phase of a uniform magnetic field. In plasma physics, we have Landau's famous damping law, which was experimentally discovered in 1965 by Malemberg and Whorton, following Landau's prediction in 1945.

In addition, we have the Landau-Lifshitz famous equations to describe the evolution of spin fields in continuous ferromagnetism. They play a key role in understanding the magnetism of non-equilibrium in a case analogous to that of the Navier-Stokes equation in fluid dynamics. Landau also calculated the diamagnetism of free electrons and electrons in metals. In elasticity, we have the Landau-Rumer theory, which deals with the direct interaction of acoustic waves with thermal phonons. It shows that the attenuation for the propagation of slow shear waves increases with the fourth power of the temperature. Landau also obtained a mass limit for neutron stars, analogous to the Chandrasekhar limit. Many Russian scientists call this the Landau-Chandrasekhar limit. In high energy physics, we have the Landau-Pomeranchuk theorem, which states that the cross sections of particles and antiparticles in interactions should approach asymptotically the same value. After the discovery of parity violation in weak interactions, Landau and independently Lee, Yang and Salam proposed the theory of the two neutrinos.

Landau has published a long series of Physics articles, with more than 30 original contributions. Among them stand out, in 1941, the theory of the Superfluidity of the Liquid Helium II and, in 1956, the Theory of the Fermi's Quantum Liquid. In his extensive scientific curriculum there are three works on detonation of explosives, developed by him during World War II (1939-1945), and only published in 1945, in the Annals of the Soviet Academy of Sciences (LIVANOVA ${ }^{(6)}$ ).

\section{The LANDAU'S LiST}

Landau drew up a list with the names of physicists he had ordered on a logarithmic scale from 0 to 5 . According to the Russian physicist Evgeny Mikhaillovich Lifshitz, quoted by CAPELLE ${ }^{(3)}$, the Landau's scale works in reverse order i.e., the lower the numerical value of the classification, the better the classified. According to CAPELLE ${ }^{(3)}$, this information appears in the foreword that Lifshitz himself wrote for the German edition of the first volume on Mechanics in the book of theoretical physics, authored by Landau and Lifshitz. The maximum value was assigned to Isaac Newton. Albert Einstein received 0.5, while Niels Bohr, Werner Heisenberg, Paul Dirac and Erwin Schrödinger were rated at 1.0. A class 2 physicist, for example, would have made a contribution 2, something on the order of $1 / 10$ of that given by a class 1 physicist. Landau himself was placed in class 2.5 , that is, equivalent to $1 / 100$ of Einstein. After about ten years, satisfied with some of his works, he declared that he had been able to rise to class 2 (PLEITEZ ${ }^{(12)}$ ).

\section{Political Aspects}

In 1939, the Russian community received with surprises the news that the country had just signed a pact of non-aggression with Nazi Germany. This event led to the arrest of thousands of men, including Landau. An unhappy socialist, but who never belonged to the Communist Party, has always shown political force against the abuses of the regime. Then, Landau, took a position contrary to the system, involving in a conflict relation with the Stalin government in calling it fascist. Confrontation with the Soviet state forces led him to arrest. He suffered a year in the hands of the organization that in the future would be called KGB, which accused him of spying for the Germans (DIDAVARI ${ }^{(4)}$ ).

Landau won the personal intervention of a Nobel Prize in Physics, Kapitza who saved him from death after a year of cold and hunger. Stalin, at the request of his friend Kapitza, decided to grant freedom to Landau in return for his work. Landau's freedom was only apparent since in the files of the secret police he remained listed as a political criminal, and he certainly did not feel free under the political regime he considered "fascist."

It is interesting to note that the difficult problem of freedom also played an important part in Landau's theoretical work in the period after his arrest, including his 1941 quantum theory of liquid helium, 
which explained Kapitza's superfluidity. Like Galileo, it was another Landau who came out of jail because he did not refuse to oversee the calculations of nuclear bombs and other scientific projects during the cold war. It is said that he received a kind of life insurance, which later guaranteed him the highest honors of the USSR, including two awards and titles. KGB secret documents revealed after the fall of the USSR showed that Landau considered himself an "educated slave" (FIOLHAIS ${ }^{(9)}$ ).

\section{Final Considerations}

Landau's wife knew Vladimir Negovsky of the Russia Medical Science Academy, a man who became very well-known, studying the problems of clinical death and biological death. Negovsky systematized a study of soldiers wounded in World War II, with very serious injuries, with the brain functioning very precariously. The doctor managed to revive many of them, such as the soldier Valentim Zderepanov who, after being mortally hit in a combat during the Second World War, was found dead. Through medical procedures, Zderepanov came back to life. From this, many Russian doctors have created a line of research to study the phenomenon of death in the laboratory, with the aid of animals. Maybe that's why Landau's wife influenced the Russian authorities in order to ensure that doctors would not turn off the devices that kept him alive.

According to LIVANOVA ${ }^{(6)}$, Landau's political biography offers us another general lesson, not only on science but also on the Soviet regime in a broader way. Even in an individual life trajectory, we can see profound influences of various complicated and often contradictory political tendencies. Its unpredictable changes and twists within the one-generation time window have even made the life of an academic scientist seem like an adventure; sometimes tragic, sometimes fortunate, above all dangerous. However, there is no preparation to experience a sudden death that maintains the integrity of the family unit. Landau would have died of a precipitous evaluation ${ }^{(6)}$, as he was diagnosed of brain death, his heart stopped four times, and he had been artificially reanimated. Sudden death, as a consequence of severe brain damage, is the precursor of multi-organ donation; thus, to the families that experience this situation, it is the first real contact with the encephalic death. On April 1, 1968, Landau's heart stopped for the fifth and last time. So at this point for reflection, a question arises: if you were an ordinary patient, would you have survived six years?

\section{REFERENCES}

[1] ARAÚJO, P. V. R.; VIEIRA, M. J. A question of death and dying. REBEN. RJ: Brazilian Journal of Nursing, n. 1, p. 361-363, 2004.

[2] BATISTA, R. S.; SCHARAMM. F. R. Plato's philosophy and the bioethics debate about the end of life. Public Health Notebook, v. 30, n. 3. Rio de Janeiro, 2004. Available in <http://www.scielo.br/scielo.php>. Accessed on: 01 March 2015.

[3] CAPELLE, K. FAPESP Online Magazine, São Paulo, August 2006, available in http://revistapesquisa .fapesp.br, accessed on 12/12/2015.

[4] DIDAVARI, R., Centenary of the birth of the physicist Lev Landau, Electronic Magazine the visions of Azerbaijan, v.4, n.1, p. 34-40, 2009, available at www.visions.az/famous_people,52, accessed on $16 / 12 / 2016$

[5] DINI, D. Notebook of Public Health, Rio de Janeiro, 22 (8): 1739-1740, August, 2006

[6] LIVANOVA, A.; Landau, a great physicist and teacher, English, Russian, Book, Illustrated edition: translated by J.B. Sykes 1980, book available in http://www.liuyanhong8.com/Landau-a-great-physicistand-teacher--or--cby-Anna-Livanova--translated-by-JB-Sykes/2/eabjih.

[7] DOROZYNSKI, A. - Landau, the wise man who died four times; trad by Joel Silveira, Editora Bloch, Rio de Janeiro, 1965, 160 p.

[8] DUARTE, P; A Death and legal effects, available in www.gostodeler.com.br/.../a_morte_e_effecções _juridicos.html, accessed on 04/02/2015.

[9] FIOLHAIS, C., LEV DAVIDOVICH LANDAU (1908-1968) - CENTENARY OF A GENIUS, DeRerum Natura, available in dererummundi.blogspot.com.../lev-davidovich-landau-1908-1968.html access on 05/09/2015

[10] FREIRE DE SÁ, M.F. Biodiversity and Right to Own Body, Publishing company DEL REI São Paulo, 2003, 154p

[11] MARQUES SOUZA, D.P., The Ethics in Organ Transplants .., Universo Jurídico magazine, available in http://www.uj.com.br/publicacoes/doutrinas, accessed on 15/12/2010 
[12] PLEITEZ, V., Brazilian Journal of Physics Teaching, vol. 25, n. 3, 2003

[13] CARUSO, F AND BASSALO, J.M.F, Biography of Landau, Publisher Physics Bookstore, 1st Edition, 76p. São Paulo 2013

\section{AUTHOR'S BIOGRAPHY}

Celso Luis Levada holds a degree in Physics from the Paulista Júlio de Mesquita Filho State University (1977), a Master's Degree in Physics and Chemistry from the University of São Paulo (1982) and a Ph.D. in Chemistry (Physics and Chemistry) from the University of São Paulo (1987).

Huemerson Maceti holds a degree in Physics from the Paulista Júlio de Mesquita Filho State University (UNESP-1996), a master's degree in Applied Physics from the Universidade Estadual Paulista Júlio de Mesquita Filho (2003).

Ivan José Lautenschleguer has a Bachelor's Degree in Physics - Univ. State University of São Paulo - Júlio de Mesquita -Rio Claro - MSc in Physics - Universidade Estadual Paulista - UNESP and PhD in Physics - Universidade Estadual Paulista - Post-doctorate in Mathematical Methods in Molecular Sciences - University of São Paulo

Miriam de Magalhães Oliveira Levada in Biology Campus Rio Claro by the Paulista Júlio de Mesquita Filho State University (1977), a Master's Degree in Biological Sciences (Zoology) by the Paulista Júlio de Mesquita Filho State University (1987), Ph.D. in Biological Sciences (Zoology) by the Paulista State University Júlio de Mesquita Child (1993)

Citation: Celso Luis Levada, Huemerson Maceti, Ivan José Lautenschleguer, Miriam de Magalhães Oliveira Levada. "The Conflicting Case of Lev Davidovich Landau's Cerebral Death". International Journal of Humanities Social Sciences and Education (IJHSSE), vol 5, no. 3, 2018, pp. 30-35 doi: http://dx.doi.org/10.20431/2349-0381.0503003.

Copyright: (C) 2018 Authors. This is an open-access article distributed under the terms of the Creative Commons Attribution License, which permits unrestricted use, distribution, and reproduction in any medium, provided the original author and source are credited. 